\title{
Cisapride for gastro-oesophageal reflux and peptic oesophagitis
}

S CUCCHIARA, A STAIANO, C CAPOZZI, C DI LORENZO, A BOCCIERI, AND S AURICCHIO

Clinical Pediatrics, Second School of Medicine, University of Naples, Naples, Italy

SUMmaRY Twenty children (age range 75 days -47 months) with reflux oesophagitis entered a random double blind trial in which they received either Cisapride (Janssen Pharmaceutical Ltd), a new prokinetic agent, or an identical placebo syrup. Diagnosis of gastro-oesophageal reflux was made by measurement of intraluminal oesophageal $\mathrm{pH}$ combined with manometry. Oesophagitis was assessed in all patients by histological examination of mucosal specimens taken during oesophagogastroduodenoscopy. Manometry, $\mathrm{pH}$ test, and endoscopy with biopsy examination were repeated at the end of the treatment period. Seventeen patients completed the trial, eight of whom were taking the drug and nine the placebo. Mean total clinical score and post-prandial reflux time (\% of reflux) significantly improved in patients in the group given Cisapride but not in the group given placebo. Furthermore, there was a significant improvement of the histological oesophagitis score only in the children in the group given Cisapride, whereas placebo was ineffective. It is concluded that Cisapride is a useful agent both for the relief of symptoms of gastro-oesophageal reflux and for the healing of peptic oesophagitis in infancy.

In the past few years there have been a number of studies on gastro-oesophageal reflux in children..$^{1-3}$ Interest has been concentrated mainly on the clinical presentation and on providing reliable diagnostic tests. A few studies, however, have been directed towards assessing the therapeutic approach of the disease. Recent trials have shown that children with reflux can be successfully treated with bethanechol chloride ${ }^{4-7}$ a cholinergic drug that stimulates intestinal smooth muscle contraction. ${ }^{8}$ In a controlled trial antacids as well as cimetidine proved to be effective for the relief of both symptoms and oesophagitis. ${ }^{9}$ Finally, a recent open study showed that domperidone, a new prokinetic agent, induced a significant improvement both in symptoms of reflux and in some gastro-oesophageal motility variables. ${ }^{10}$

In only one study, however, was the trial designed in a double blind fashion. ${ }^{4}$ As gastro-oesophageal reflux has a favourable natural history in children, ${ }^{11}$ double blind controlled trials would seem to be advisable to assess the true place of medical treatment of reflux in children.

Cisapride (R 51 619, Janssen Pharmaceutical Ltd) is a new prokinetic drug that stimulates smooth muscle cell contraction of the gastrointestinal tract. ${ }^{12}$ This prompted us to investigate the effect of oral Cisapride compared with placebo in the treatment of children with symptomatic gastrooesophageal reflux and peptic oesophagitis.

\section{Patients and methods}

Twenty patients, nine boys and 11 girls, aged 75 days -47 months, with a diagnosis of gastrooesophageal reflux and oesophagitis, were entered into a double blind trial to compare Cisapride syrup $(1 \mathrm{mg} / \mathrm{ml})$ at a dose of $0.3 \mathrm{mg} / \mathrm{kg}$ three times a day before meals with placebo syrup, which was identical to Cisapride in taste and appearance, taken at the same dose, over eight weeks. In each patient diagnosis of gastro-oesophageal reflux was based on $\mathrm{pH}$-metric demonstration of acid reflux. Fibreoptic endoscopy and biopsy examination revealed oesophagitis in all 20 patients. Infectious, neurologic, metabolic, and renal disorders were carefully excluded. Abnormalities of the oesophagus, stomach, and duodenum were excluded by upper intestinal $x$ ray examination. Parents gave informed consent and the study was approved by the ethical committee of our faculty.

Gastro-oesophageal reflux was detected by a five hour $\mathrm{pH}$ study, performed after ingestion of apple juice $(15-20 \mathrm{cc} / \mathrm{kg})$, with a $\mathrm{pH}$ of 4 . A small flexible 
electrode (MI 506, Microelectrodes Inc, Londonderry, New Hampshire, United States of America), calibrated with buffers at $\mathrm{pH}$ levels of 7.0 and 4.0 , was introduced nasally and located at $87 \%$ of the distance from the nares to the lower oesophageal sphincter previously determined by manometry. Gastro-oesophageal reflux was defined as a fall in intra-oesophageal $\mathrm{pH}$ below 4 for at least 20 seconds.

Manometry was performed by a triple lumen catheter with side recording orifices spaced $2.5 \mathrm{~cm}$ apart and perfused with bubble free water at a low compliance infusion system (Arndorfer, Med Spec Co, Greendale, Wisconsin, USA). The probe was initially located into the stomach and subsequently moved across the lower oesophageal sphincter $0.5 \mathrm{~cm}$ at a time, remaining at each station long enough to obtain a stable pressure recording. Lower oesophageal sphincter pressure was determined as mean pressure of the three orifices, with the gastric pressure as zero reference, taking the mid-respiratory value. Motor activity of the distal oesophagus was recorded by placing the distal side hole of the catheter immediately proximal to the lower oesophageal sphincter. Oesophageal waves were elicited by administering $2 \mathrm{ml}$ of $5 \%$ dextrose. Only waves preceded by at least 30 seconds of silent motor activity in the oesophagus were taken into account. Amplitude of peristalsis $(\mathrm{mm} \mathrm{Hg}$ ) was measured by subtracting the mean resting oesophageal pressure from the peak of the waves. Both oesophageal manometry and $\mathrm{pH}$ study were performed during the same session after a two to three hour fast without sedation. Patients with diagnosis of reflux underwent upper endoscopy with a small fibreoptic endoscope (GIF PX Olympus).

Mucosal erythema or oedema were not considered to be reliable findings of oesophagitis. Endoscopic lesions, such as friability, exudate, erosions, or ulcerations, were considered to be important markers of oesophagitis. During endoscopy, biopsy specimens were taken from the oesophageal mucosa, irrespective of its appearance, and examined by a histopathologist, who was unaware of the endoscopic findings. The degree of oesophagitis was histologically defined as 'mild' if there was basal cell hyperplasia and extension of the papillae, 'moderate' if there was also an increased cellularity of the lamina propia, and 'severe' if there were also signs of mucosal ulcerations.

Blood counts, urinalysis, and determination of serum transaminase and alkaline phosphatase activities, and bilirubin, creatinine, and urea concentrations were taken before randomisation to either Cisapride or placebo. During the study, frequent assessments were made of severity and frequency of symptoms and drug use. Manometry, $\mathrm{pH}$ study, endoscopy, and biopsy examination were repeated within two days before the end of the trial for comparison with pretreatment data. At completion of the trial the patients were classified as 'cured' if clinical, pH-metric, and histological variables had normalised, 'improved' if at least one of these three variables had ameliorated, and 'unchanged' or 'worsened' if no improvement or worsening was observed, respectively. Throughout the trial, parents were provided with diary cards to keep a daily record of the symptoms and physical signs. A scoring system was used to evaluate symptoms and physical signs as well as oesophageal histology of the patients (Table 1).

Data were analysed using either Student's $t$ test or rank sum non-parametric tests. p Values $<0.05$ were considered significant.

\section{Results}

Three patients failed to complete the study and were withdrawn, two because of febrile upper respiratory infections and one who failed to take the drug continuously. Eight patients (age range 90 days -36 months) were treated with the drug and nine (age

Table 1 Scoring system for symptoms or physical signs and for oesophagitis assessed by histology

\begin{tabular}{|c|c|c|}
\hline & Evaluation & $\begin{array}{l}\text { Score } \\
\text { (points) }\end{array}$ \\
\hline \multicolumn{3}{|l|}{ Symptoms or physical signs } \\
\hline \multicolumn{3}{|l|}{ Vomiting or regurgitation, or } \\
\hline both (episodes/week) & None & 0 \\
\hline & $1-3$ & 3 \\
\hline & $>3<7$ & 6 \\
\hline & $>7$ & 9 \\
\hline \multicolumn{3}{|l|}{ Pneumonia or asthma } \\
\hline \multirow[t]{3}{*}{ (episodes/two months) } & None & 0 \\
\hline & 1 & 5 \\
\hline & $>1$ & 10 \\
\hline \multirow[t]{4}{*}{ Apnoea (episodes/week) } & None & 0 \\
\hline & 1 & 6 \\
\hline & $>2<5$ & 9 \\
\hline & $>5$ & 12 \\
\hline \multicolumn{3}{|l|}{ Haematemesis } \\
\hline \multirow[t]{3}{*}{ (episodes/two months) } & None & 0 \\
\hline & $1-2$ & 5 \\
\hline & $>2$ & 10 \\
\hline \multicolumn{3}{|l|}{ Heartburn, dysphagia } \\
\hline \multirow[t]{4}{*}{ (episodes/week) } & None & 0 \\
\hline & $1-3$ & 2 \\
\hline & $>3<7$ & 4 \\
\hline & $>7$ & 6 \\
\hline \multirow[t]{5}{*}{ Weight/height ratio (centile) } & $>50 \mathrm{th}$ & 0 \\
\hline & $>25 \mathrm{th}<50 \mathrm{th}$ & 1 \\
\hline & $>10$ th $<25$ th & 2 \\
\hline & 5 th-10th & 5 \\
\hline & $<5$ th & 10 \\
\hline \multirow[t]{4}{*}{ Oesophagitis (histology) } & Normal & 0 \\
\hline & Mild degree & 3 \\
\hline & Moderate degree & 6 \\
\hline & Severe degree & 9 \\
\hline
\end{tabular}


range 75 days -47 months) with the placebo. The two groups were comparable for clinical and histological scores and for percentage of reflux time at the $\mathrm{pH}$ study.

Four patients on Cisapride and one on placebo were healed, two patients on Cisapride and one on placebo were considered to have improved, and nine children remained unchanged or worsened. Of these, two were in the Cisapride group and seven in the placebo group. As shown in Table 2, the posttreatment clinical score, percentage of reflux time, and histological score for oesophagitis were significantly better in the group treated with Cisapride but showed no change in the group treated with placebo. Furthermore, at the end of the trial amplitude of peristalsis was significantly increased only in the Cisapride group, whereas lower oesophageal sphincter pressure and mean duration of episodes of reflux showed no significant change in either groups. The percentage improvement from the pre-study baseline in clinical score and duration of reflux was higher in the Cisapride group than in the placebo group (Figure). There was a significant difference, however, only for the percentage change of the clinical score.

Four patients on Cisapride (three with moderate and one with mild oesophagitis before treatment) were totally healed. Two of the remaining four patients on Cisapride had severe oesophagitis at the beginning of the study, one of whom remained unchanged and one of whom improved. The other two patients on Cisapride had moderate oesophagitis, and again one remained unchanged and one improved.

Of the patients on placebo, one who initially had severe oesophagitis remained unchanged at the
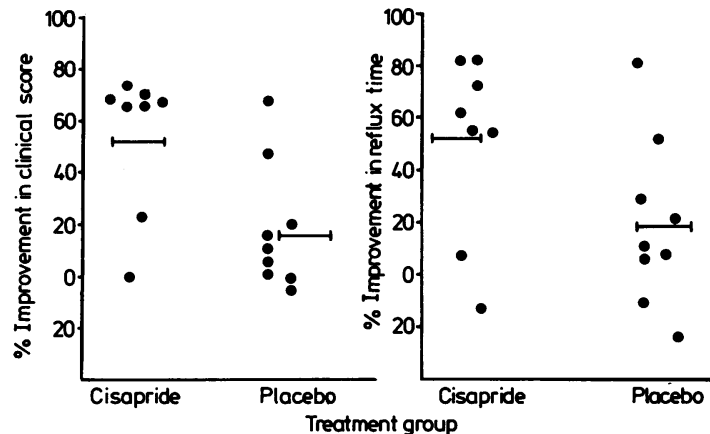

Figure Percentage improvement from pre-study baseline in clinical and reflux time for each patient at completion of the double blind trial. Mean (SD) clinical score for the Cisapride group was 54.05 (27.69) and for the placebo group was 17.69 (22.64) (Student's t test, $p<0.01$; Wilcoxon rank sum test, $p<0 \cdot 05)$. Mean $(S D)$ reflux time for the Cisapride group was $50.92(36.7)$ and for the placebo group was 19.83 (30.7) (Student's t test, $p=0.07$, not significant; Wilcoxon rank sum test, $p=0 \cdot 11$, not significant).

completion of the trial. Six had moderate oesophagitis at the start of the trial. Of these, three failed to improve, two had an improvement in the histological appearance, and one healed. Finally, two patients who had mild oesophagitis at the start of the trial remained unchanged at the end.

No significant changes occurred in the biochemical variables. No untoward clinical signs or symptoms were observed during the trial.

\section{Discussion}

Major advances have recently been made in under-

Table 2 Results obtained in 17 patients with gastro-oesophageal reflux after eight weeks of treatment with Cisapride or placebo. Results are given as mean (SD)

\begin{tabular}{|c|c|c|c|c|c|c|c|c|}
\hline & \multicolumn{8}{|c|}{ Treatment group } \\
\hline & \multicolumn{4}{|l|}{ Cisapride } & \multicolumn{4}{|l|}{ Placebo } \\
\hline & $\begin{array}{l}\text { Before } \\
\text { treatment }\end{array}$ & $\begin{array}{l}\text { After } \\
\text { treatment }\end{array}$ & $\begin{array}{l}\text { Student's } \\
\mathrm{t} \text { test }\end{array}$ & $\begin{array}{l}\text { Signed } \\
\text { rank test }\end{array}$ & $\begin{array}{l}\text { Before } \\
\text { treatment }\end{array}$ & $\begin{array}{l}\text { After } \\
\text { treatment }\end{array}$ & $\begin{array}{l}\text { Student's } \\
\text { t test }\end{array}$ & $\begin{array}{l}\text { Signed } \\
\text { rank } \\
\text { test }\end{array}$ \\
\hline Clinical score* & $16 \cdot 25(7 \cdot 1)$ & $7 \cdot 87(7 \cdot 05)$ & $\mathrm{p}<0.01$ & $\mathrm{p}<0.05$ & $13 \cdot 5(4 \cdot 15)$ & $10 \cdot 8(3.95)$ & NS & NS \\
\hline$\%$ Of reflux time* & $25.68(11.65)$ & $11 \cdot 83(11 \cdot 07)$ & $\mathrm{p}<0.05$ & $p<0.05$ & $32 \cdot 71(18 \cdot 35)$ & $23.85(13 \cdot 57)$ & NS & NS \\
\hline $\begin{array}{l}\text { Duration of episodes } \\
\text { of gastro-oesophageal } \\
\text { reflex (min) }\end{array}$ & $4.28(0.71)$ & $4 \cdot 12(1 \cdot 11)$ & NS & NS & $4.60(0.98)$ & $4 \cdot 51(1.0)$ & NS & NS \\
\hline $\begin{array}{l}\text { Lower oesophageal } \\
\text { sphincter pressure } \\
(\mathrm{mm} \mathrm{Hg})\end{array}$ & $20 \cdot 62(7 \cdot 53)$ & $19 \cdot 62(4 \cdot 62)$ & NS & NS & $20 \cdot 55(5 \cdot 87)$ & $22 \cdot 22(7 \cdot 10)$ & NS & NS \\
\hline $\begin{array}{l}\text { Peristalsis } \\
\text { amplitude }(\mathrm{mm} \mathrm{Hg}) \\
\text { Histological score }\end{array}$ & $46 \cdot 9(15 \cdot 7)$ & $57 \cdot 7(11 \cdot 5)$ & $\mathrm{p}<0.05$ & $\mathrm{p}<0.05$ & $49 \cdot 92(18 \cdot 10)$ & $50 \cdot 07(10 \cdot 11)$ & NS & NS \\
\hline for oesophagitis & $6.37(1.92)$ & $3 \cdot 0(3 \cdot 58)$ & $\mathrm{p}<0.05$ & $\mathrm{p}<0.05$ & $5.66(1.80)$ & $4.33(2 \cdot 64)$ & NS & NS \\
\hline
\end{tabular}

${ }^{*}$ No significant difference in the two groups of patients for the clinical and histological scores and percentage of reflux time before treatment. NS $=$ Not significant 
standing the physiopathological mechanisms of gastro-oesophageal reflux. ${ }^{13}$ 14 There is evidence that the pathogenesis of reflux has many components, such as lower oesophageal sphincter incompetence, abnormal oesophageal peristalsis, delayed gastric emptying, and oesophageal mucosal damage from gastric content. Treatment of reflux might be directed, therefore, towards either counteracting upper gastrointestinal motor defects or altering the character of the gastric content available for reflux. Cisapride is a new prokinetic drug that facilitates release of acetylcholine from the myenteric plexus and has no dopamine blocking properties, and in vivo and in vitro studies have shown that it increases lower oesophageal sphincter pressure and amplitude of oesophageal peristalsis and improves gastric emptying (Gilbert RJ, Dodds WJ, Karhilas PJ, Hogan WJ, Lipman S. Double-blind assessment of the effect of intravenous and oral Cisapride on oesophageal motor function. Abstract presented at First International Investigations Meeting on Cisapride, Brussels, December 1985. ${ }^{15}$ For this reason, the drug has great potential in the treatment of gastro-oesophageal reflux.

The results of this trial indicate that Cisapride is more effective than placebo in the relief of symptoms of gastro-oesophageal reflux in children. Symptomatic control in patients treated with Cisapride was documented both by decreased duration of reflux time during the repeated $\mathrm{pH}$ test and by significant improvement in the oesophageal histological damage. No changes in the lower oesophageal sphincter pressure were noted between the results of manometry before and after treatment in the two groups. Although the children on Cisapride showed a slightly significant increase of oesophageal peristaltic amplitude compared with those on placebo, however, amplitude of peristalsis was not remarkably decreased before treatment in either groups. Moreover, basal mean values of lower oesophageal sphincter pressure in all our patients were not different from that of a normal paediatric population. ${ }^{16}$ This would suggest that patients included in the study as a whole had moderate reflux. Cisapride caused a significant reduction of the reflux time, whereas mean duration of reflux was unchanged. This finding was mainly due to a decreased frequency of episodes of reflux and implies that the drug might be more effective on the mechanisms related to the frequency of episodes of reflux, such as lower oesophageal sphincter pressure and gastric emptying. Cisapride has also been shown to improve gastric emptying: documentation of this effect is lacking in our study.

Cisapride was also more effective than placebo in improving histological changes of oesophagitis. Of the 17 patients included in the study, however, only three had severe oesophagitis; the remaining 14 had mild or moderate oesophagitis. The effectiveness of Cisapride in the treatment of more severe reflux oesophagitis remains to be proved.

The manometric findings, such as normal (or slightly decreased) pressure of peristalsis and lower oesophageal sphincter absence of non-specific oesophageal motor defects, and the prevailing moderate degree of oesophagitis, indicate that our group of selected patients was not seriously affected. It would be desirable, therefore, for future trials with Cisapride in children affected by gastro-oesophageal reflux to include more patients with severe reflux oesophagitis.

\section{References}

1 Herbst JJ. Gastroesophageal reflux. J Pediatr 1981;98:859-70.

2 Jewett TC Jr. Sicgel M. Hiatal hernia and gastroesophageal reflux. J Pediatr Gastroenterol Nutr 1984;3:340-5.

${ }^{3}$ Weihrauch TR. Gastro-oesophageal reflux-pathogenesis and clinical implications. Eur J Pediatr 1985;144:215-8.

${ }^{+}$Euler AR. Use of bethanechol for the treatment of gastroesophageal reflux. J Pediatr 1980;96:321-4.

s Strickland AD, Chang JHT. Results of treatment of gastroesophageal reflux with bethanechol. J Pediatr 1983;103: 311-5.

${ }^{6}$ Sondheimer JM, Mintz HL, Michaels M. Bethanechol treatment of gastroesophageal reflux in infants: effects on continuous esophageal pH records. J Pediatr 1984;104:128-31.

${ }^{7}$ Levi P. Marmo F, Saluzzo C, et al. Bethanechol versus antacids in the treatment of gastroesophageal reflux. Helv Paediatr Acta 1985;40:349-59.

${ }^{*}$ Humphries TJ, Castell DO. Effects of bethanechol on parameters of esophageal peristalsis. Dig Dis Sci 1981;26:129-32.

" Cucchiara S. Staiano A, Romaniello G, Capobianco S, Auricchio $\mathrm{S}$. Antacids and cimetidine treatment for gastroesophageal reflux and peptic oesophagitis. Arch Dis Child 1984;59:842-7.

10 Grill BB, Hillemeier AC. Semeraro LA, McCallum RW, Gryboski JD. Effects of domperidone therapy on symptoms and upper gastrointestinal motility in infants with gastroesophageal reflux. J Pediatr 1985;106:311-6.

11 Carre IJ. Management of gastroesophageal reflux. Arch Dis Child 1985;60:71-5.

12 Van Nueten JM, Schuurkes JAJ. Stimulating effects of Cisapride on isolated preparations of stomach, small and large intestine of the guinea pig. Gastroenterology 1984;86:1288.

1.3 Cohen S, Snape WJ. The pathophysiology and treatment of gastroesophageal reflux disease. Arch Intern Med 1978;138: 1398-401.

${ }^{14}$ Dodds WJ. Hogan WJ, Helm JF, Dent J. Pathogenesis of reflux esophagitis. Gastroenterology 1981;81:376-94.

15 Jian R, Ducrot F, Pieddeloup C, Mary JY, Bernier JJ. Measurement of gastric emptying in dyspeptic patients: effect of a new gastrokinetic agent (cisapride). Gut 1985:26:352-8.

${ }^{16}$ Cucchiara S, Staiano A, Di Lorenzo C, et al. Esophageal motor abnormalities in children with gastroesophageal reflux and peptic esophagitis. J Pediatr 1986;108:907-10.

Correspondence to Dr S Cucchiara. Clinica Pediatrica. Il Facoltà di Medicina, Università di Napoli. Via S Pansini 5, 80131 Naples. Italy.

Received 9 December 1986 